\title{
Changes in Body Mass Index and its Relationships to Other Cardiovascular Risk Factors among Japanese Population: Results from the 1980 and 1990 National Cardiovascular Surveys in Japan
}

\author{
Longjian Liu ${ }^{1,2}$, Sohel R Choudhury ${ }^{1}$, Akira Okayama ${ }^{1}$, Takehito Hayakawa ${ }^{1}$, \\ Yoshikuni Kita ${ }^{1}$, and Hirotsugu Ueshima ${ }^{1}$
}

\begin{abstract}
Few studies have attempted to investigate the changes in body mass index (BMI) and its relationship to other cardiovascular factors in Asian populations, including Japanese. Data from two national cross-sectional surveys on circulatory disorders in 1980 and 1990 in Japan were used in this study. The sample consisted of 10,556 participants in the 1980 survey and 8,385 in the 1990 survey, aged $\geq 30$ years. The results show that after adjusting for age, smoking, alcohol consumption (ALC) and daily life physical activity (PA), mean BMI increased $0.49 \mathrm{~kg} / \mathrm{m}^{2}(95 \%$ confidence interval: $0.34-0.65)$ in men aged $30-59$ and $0.61 \mathrm{~kg} / \mathrm{m}^{2}(0.37-0.86)$ in those aged $\geq 60$ from 1980 to 1990 . In women, however, mean BMl decreased $0.24 \mathrm{~kg} / \mathrm{m}^{2}(-0.390 .09)$ in those aged $30-59$ and increased $0.38 \mathrm{~kg} / \mathrm{m}^{2}(0.12-0.64)$ in those aged $\geq 60$. BMI was significantly associated with hypertension, diabetes and hypercholesterolaemia. In both genders, cu-smokers had lower mean BMl than never smokers, while among the cu-smokers, mean BMI was positively associated with the number of cigarettes smoked per day. In men, BMI was positively associated with ALC and negatively associated with PA, while in women, BMI was negatively associated with ALC and positively associated with PA. The results suggest that BMI has significantly increased in men and in elderly women. BMI, even in the Japanese population who are characterized by relative low BMI, is significantly associated with several cardiovascular risk factors. J Epidemiol, $1999 ; 9: 163-174$
\end{abstract}

changes, body mass index, cardiovascular risk factors, Japanese

In Japan, malignant neoplasm and cardiovascular disease are major causes of death. Among the major causes of death, ageadjusted mortality rates from both cerebrovascular disease and heart disease, including coronary heart disease (CHD), have been declining since 1970 . These changes have been thought to result primarily from the control of high blood pressure, including both primary and secondary preventive measures ${ }^{1}$. However, since the intake of fat has increased with lifestyle westernization, there is some concern that both mortality and morbidity from CHD may soon show an increasing trend ${ }^{2}$. If potentially epidemic CHD is to be prevented, it is important to understand the trends in cardiovascular risk factors. Some previous studies have reported an increase in serum cholesterol concentrations and an increase in the prevalence of diabetes mellitus in Japan ${ }^{3-5)}$. However, little attention has been paid to changes in the body mass index (weight $(\mathrm{kg}) / \mathrm{height}\left(\mathrm{m}^{2}\right)$ ). Furthermore, possibly because Asian populations, including Japanese, have a much lower body mass index (BMI) than Caucasians, the associations between BMI and other cardiovascular factors are not well understood in Asian populations. In the present study, we used data of the 1980 and 1990 National Cardiovascular Surveys in Japan to investigate the changes in BMI, and the associations between BMI and the prevalence of hypertension, diabetes mellitus, hypercholesterolaemia, cigarette smoking, alcohol consumption and daily life physical activity.

Received November 9, 1998 ; accepted December 17, 1998.

${ }^{1}$ Department of Health Science Shiga University of Medical Science Seta, Tsukinowa-Cho, Otsu, Shiga, $520-2192$ Japan.

'Department of Epidemiology Chongqing University of Medical Science 1 Yixueyuan Road, Chongqing, 400046 China.

Address for correspondence: Dr. Longjian Liu Department of Health Science Shiga University of Medical Science Seta, Tsukinowa-Cho, Otsu, Shiga, 520-2192 Japan. 


\section{METHODS}

\section{Design of the surveys}

The Ministry of Health and Welfare of Japan organized the 1980 and 1990 National Cardiovascular Surveys. The two surveys had a similar study design, but were independently carried out. For the 1980 survey, 300 districts were randomly selected from the "Survey of Sample Districts of Population for Statistics of Health and Welfare" ${ }^{\circ}$. The subjects were all residents aged 30 or older by the 1st of November 1980 . The total number of eligible residents was 13,771 . However, 10,897 persons were actually examined in the survey. Consequently, the overall participation rate was $79.1 \%(73.8 \%$ for men and $84.3 \%$ for women). In the 1990 survey, 300 districts were drawn at random from the 1990 National Livelihood Survey of households and household members in all parts of Japan ${ }^{\text {D }}$. The total number of eligible residents using the same age criterion as in the 1980 survey was 10,956 . However, only 8,926 individuals were actually examined, for a participation rate of $81.5 \%: 76.1 \%$ for men and $86 \%$ for women. In the present study, subjects who had completed physical examinations, blood tests and questionnaire surveys were included in the data analyses. Overall, the sample size was 10,556 in 1980 and 8,385 in 1990.

The methods used for the examinations were described in detail in the reports on the two surveys ${ }^{6,7}$. Briefly, height $(\mathrm{cm})$ and weight $(\mathrm{kg})$ were measured in bare feet and in light clothing. Blood pressure was measured in $\mathrm{mmHg}$ in each participant's right arm, with a standard mercury sphygmomanometer. Urinary glucose was tested by paper colorimetry, and the results were classified as negative or positive. Total cholesterol was measured by an enzymatic method with a Hitachi 736-60. For both the 1980 and 1990 surveys, cooperation was obtained from the Department of Epidemiology and Mass Examination for Cardiovascular Diseases, Osaka Medical Center for Cancer and Cardiovascular Diseases, which has 16 years of experience with the U.S. CDC-NHLBI Lipid Standardization Program of the Centers for Disease Control ${ }^{6,7}$.

\section{Statistical methods}

BMI was calculated as weight $(\mathrm{kg}) / \mathrm{height}\left(/ \mathrm{m}^{2}\right)$ and was used as a continuous variable in the data analysis. It was also categorized into four levels according to quartiles of the BMI distributions of subjects in the 1980 and 1990 surveys. Overweight was classified as BMI $\geq 25 \mathrm{~kg} / \mathrm{m}^{2}$.

Hypertensive subjects were those who had systolic blood pressure $\geq 160 \mathrm{mmHg}$ or diastolic blood pressure $\geq 95 \mathrm{mmHg}$, or who were under treatment with antihypertensive agents. In both 1980 and 1990 surveys, although blood glucose levels were determined, however, methods of their measurements were different, and glycohemoglobin Alc was tested only in the 1990 survey. Therefore, in the present study, subjects were classified as diabetes mellitus (DM) for any of the following conditions: self-reported history of DM or positive urinary glucose test because only these were available and comparable as crude indices of DM in the 1980 and 1990 surveys ${ }^{6-8)}$. Hypercholesterolaemia was defined as total cholesterol $\geq 220$ $\mathrm{mg} / \mathrm{dl}$.

Cigarette smoking status was classified as never smoking, ex-smoking or cu-smoking (current smoking). Cu-smokers were further divided into those who smoked 1-20, 21-40 and $\geq$ 41 cigarettes per day. According to the available data on drinking habits in the 1980 and 1990 surveys, alcohol consumption was divided into three categories: never, ex- and cu-drinking. Daily life physical activity were classified into three categories that are usually used in Japan. This classification is based on both occupational and leisure time physical activity. The category I is the least active group, and the category III is the most. The category I (light) usually includes sedentary workers and housewives without infants and toddlers. The category II (moderate) includes industry workers and self-employed women. The category III (heavy) includes farmers, fishermen and professorial sportsmen.

To test differences in mean BMI and the prevalence of overweight between the 1980 and 1990 surveys, t-tests and Chisquare tests were used by gender and by five 10-year agegroups (30-39, 40-49, 50-59, 60-69 and 70 years or over). The changes in BMI, by gender and age (30-59 and 60 or over), were further examined by adjusting for age and three lifestyle factors (smoking, alcohol consumption and daily life physical activity) using analyses of covariance method. To examine the associations between BMI and hypertension, DM and hypercholesterolaemia, logistic regression models were used to calculate multi-adjusted odds ratios (OR) and the $95 \%$ confidence interval $(95 \% \mathrm{CI})$ of $\mathrm{OR}$. In these models, hypertension, diabetes or hypercholesterolaemia was the dependent variable (binary, $0=$ no, 1=yes), and BMI was the independent variable (by quartiles). The multi-adjusted factors were age, smoking, alcohol consumption and daily life physical activity. To explore the relationships between BMI and three lifestyle factors (smoking, alcohol consumption and daily life physical activity), age-adjusted mean BMI was compared between three categories of each factor by gender and survey year. Finally, the 1980 and 1990 surveys were combined and further analyzed using two multiple linear regression models. In these linear regression models, BMI was the dependent variable (continuous) and lifestyle factors were the independent variables by adjusting for survey year and age. Model 1 included all of the subjects in the total combined sample, while model 2 included subjects who were cu-smokers. In model 1, survey year was coded as 0 for the 1980 survey and 10 for the 1990 survey, age was used as a continuous variable (years), ex-smoking and cusmoking were coded as two dummy variables $(0=$ no, $1=$ yes $)$, drinking habits were coded as: $0=$ never drinking, $1=$ ex-drink- 
Table 1. Characteristics of the study participants in 1980 and 1990 for men and women.

\begin{tabular}{|c|c|c|c|c|c|c|}
\hline & \multicolumn{3}{|c|}{1980} & \multicolumn{3}{|c|}{1990} \\
\hline & $\mathrm{N}$ & Mean/rate & SD & $\mathbf{N}$ & Mean/rate & SD \\
\hline \multicolumn{7}{|l|}{ Men } \\
\hline Age & 4643 & 50 & 13.40 & 3500 & 53 & 13.72 \\
\hline Body mass index $\left(\mathrm{kg} / \mathrm{m}^{2}\right)$ & 4641 & 22.50 & 2.87 & 3496 & 22.96 & 3.00 \\
\hline Systolic BP (mmHg) & 4640 & 138 & 21.06 & 3500 & 138 & 20.02 \\
\hline Diastolic BP (mmHg) & 4640 & 84 & 12.37 & 3500 & 84 & 11.65 \\
\hline Total cholesterol (mg/dl) & 4637 & 186.37 & 32.89 & 3260 & 198.63 & 36.84 \\
\hline \multicolumn{7}{|l|}{ Cigarette smoking (\%) } \\
\hline Never smoker & 843 & 18.2 & & 739 & 21.1 & \\
\hline Ex-smoker & 872 & 18.8 & & 828 & 23.7 & \\
\hline Cu-smoker & 2920 & 63.0 & & 1933 & 55.2 & \\
\hline \multicolumn{7}{|l|}{ Alcohol consumption $(\%)$} \\
\hline Never drinker & 924 & 19.9 & & 1230 & 35.1 & \\
\hline Ex-drinker & 268 & 5.8 & & 249 & 7.1 & \\
\hline Cu-drinker & 3444 & 74.3 & & 2021 & 57.7 & \\
\hline \multicolumn{7}{|l|}{ Daily life physical activity (\%) ${ }^{\text {a) }}$} \\
\hline Light & 1324 & 28.6 & & 1722 & 49.2 & \\
\hline Moderate & 2706 & 58.4 & & 1331 & 38.0 & \\
\hline Heavy & 603 & 13.0 & & 447 & 12.8 & \\
\hline Hypertension (\%) ${ }^{\text {b) }}$ & 1287 & 27.7 & & 978 & 27.9 & \\
\hline Diabetes mellitus $(\%)^{c)}$ & 319 & 6.9 & & 335 & 10.0 & \\
\hline Hypercholesterolaemia (\%) d) & 700 & 15.1 & & 878 & 26.9 & \\
\hline \multicolumn{7}{|l|}{ Women } \\
\hline Age & 5913 & 50 & 13.47 & 4885 & 53 & 14.11 \\
\hline Body mass index $\left(\mathrm{kg} / \mathrm{m}^{2}\right)$ & 5913 & 22.83 & 3.38 & 4879 & 22.84 & 3.32 \\
\hline Systolic BP (mmHg) & 5909 & 134 & 21.74 & 4884 & 134 & 20.80 \\
\hline Diastolic BP (mmHg) & 5909 & 80 & 12.00 & 4884 & 80 & 11.73 \\
\hline Total cholesterol (mg/dl) & 5905 & 191.21 & 33.89 & 4565 & 207.04 & 38.74 \\
\hline \multicolumn{7}{|l|}{ Cigarette smoking (\%) } \\
\hline Never smoker & 5186 & 87.8 & & 4286 & 87.8 & \\
\hline Ex-smoker & 142 & 2.4 & & 133 & 2.7 & \\
\hline Cu-smoker & 578 & 9.8 & & 465 & 9.5 & \\
\hline \multicolumn{7}{|l|}{ Alcohol consumption (\%) } \\
\hline Never drinker & 4603 & 78.0 & & 4513 & 92.4 & \\
\hline Ex-drinker & 99 & 1.7 & & 54 & 1.1 & \\
\hline Cu-drinker & 1200 & 20.3 & & 317 & 6.5 & \\
\hline \multicolumn{7}{|l|}{ Daily life physical activity $(\%)^{\text {at }}$} \\
\hline Light & 2757 & 47.1 & & 2709 & 55.5 & \\
\hline Moderate & 2801 & 47.8 & & 1855 & 38.0 & \\
\hline Heavy & 299 & 5.1 & & 321 & 6.6 & \\
\hline Hypertension (\%) ${ }^{\mathbf{b})}$ & 1320 & 22.3 & & 1203 & 24.6 & \\
\hline Diabetes mellitus $(\%)^{\mathrm{c})}$ & 186 & 3.1 & & 236 & 5.0 & \\
\hline Hypercholesterolaemia (\%) ${ }^{d)}$ & 1133 & 19.2 & & 1578 & 34.6 & \\
\hline
\end{tabular}

a) Daily life physical activity was classified based on subject's occupational and leisure time physical activity.

b) Subjects were classified as having hypertension for those who had SBP $\geqq 160$ or DBP $\geqq 95 \mathrm{mmHg}$, or who were under treatment with antihypertensive agents.

c) Subjects were classified as diabetes mellitus (DM) for any of the following conditions: self-reported history of DM or positive urinary glucose.

d) Hypercholesterolaemia was defined as total cholesterol $\geqq 220 \mathrm{mg} / \mathrm{dl}$. 
ing and $2=c u$-drinking, and daily life physical activity was coded as: $0=$ light, $1=$ moderate and $2=$ heavy. In model 2 , the same coding values for adjusted and independent variables were used as in model 1, except that smoking status was coded according to the number of cigarettes smoked daily (1, 2 and 3 for subjects who smoked 1-20, 21-40 and $\geq 41$ cigarettes per day). SPSS ver. 7.5 software was used for all data analyses ${ }^{\text {? }}$.

\section{RESULTS}

\section{General characteristics of the two surveys}

Table 1 shows the general characteristics of the 1980 and 1990 surveys. Both men and women were older in the 1990 survey than in 1980 (mean age 53 vs. 50 years for both genders). Mean BMI in men was higher in 1990 than in 1980 ( $\left.22.96 \mathrm{vs.} 22.5 \mathrm{~kg} / \mathrm{m}^{2}\right)$, but appeared to be similar in women between the two surveys ( $\left.22.84 \mathrm{vs.} 22.83 \mathrm{~kg} / \mathrm{m}^{2}\right)$. The mean systolic blood pressure (SBP) and diastolic blood pressure (DBP) were similar in the 1980 and 1990 surveys in both genders. Mean total cholesterol was higher in 1990 than in 1980 in both genders. The prevalence of cu-smoking and cu-drinking were lower in 1990 than in 1980 in men and women. The percentage of subjects who engaged in light physical activity was higher in 1990 than in 1980 in men and women. The prevalence of hypertension was similar between 1980 and 1990 in men, but was higher in 1990 in women. The prevalence of DM and hypercholesterolaemia were higher in 1990 than in 1980 in men and women.

Changes in body mass index and prevalence of overweight by gender and age

Table 2 shows that, among men, mean BMI and the prevalence of overweight significantly increased from 1980 to 1990 in the five 10-year age groups. Mean BMI increased between 0.37 and $0.67 \mathrm{~kg} / \mathrm{m}^{2}$, and the prevalence of overweight increased from 4.4 to 6.1 percentage points. In women aged $<50$ years, mean BMI significantly decreased from 0.32 to $0.39 \mathrm{~kg} / \mathrm{m}^{2}$, while mean BMI in those aged $60-69$ significantly increased $0.49 \mathrm{~kg} / \mathrm{m}^{2}$ from 1980 to 1990 . Increased BMI was also observed in women aged 50-59 and in those aged $\geq 70$

Table 2. Age specific mean body mass index $\left(\mathrm{kg} / \mathrm{m}^{2}\right)$ and prevalence of overweight $\left(\mathrm{BMI} \geqq 25 \mathrm{~kg} / \mathrm{m}^{2}\right)$, and their changes from 1980 to 1990 for men and women.

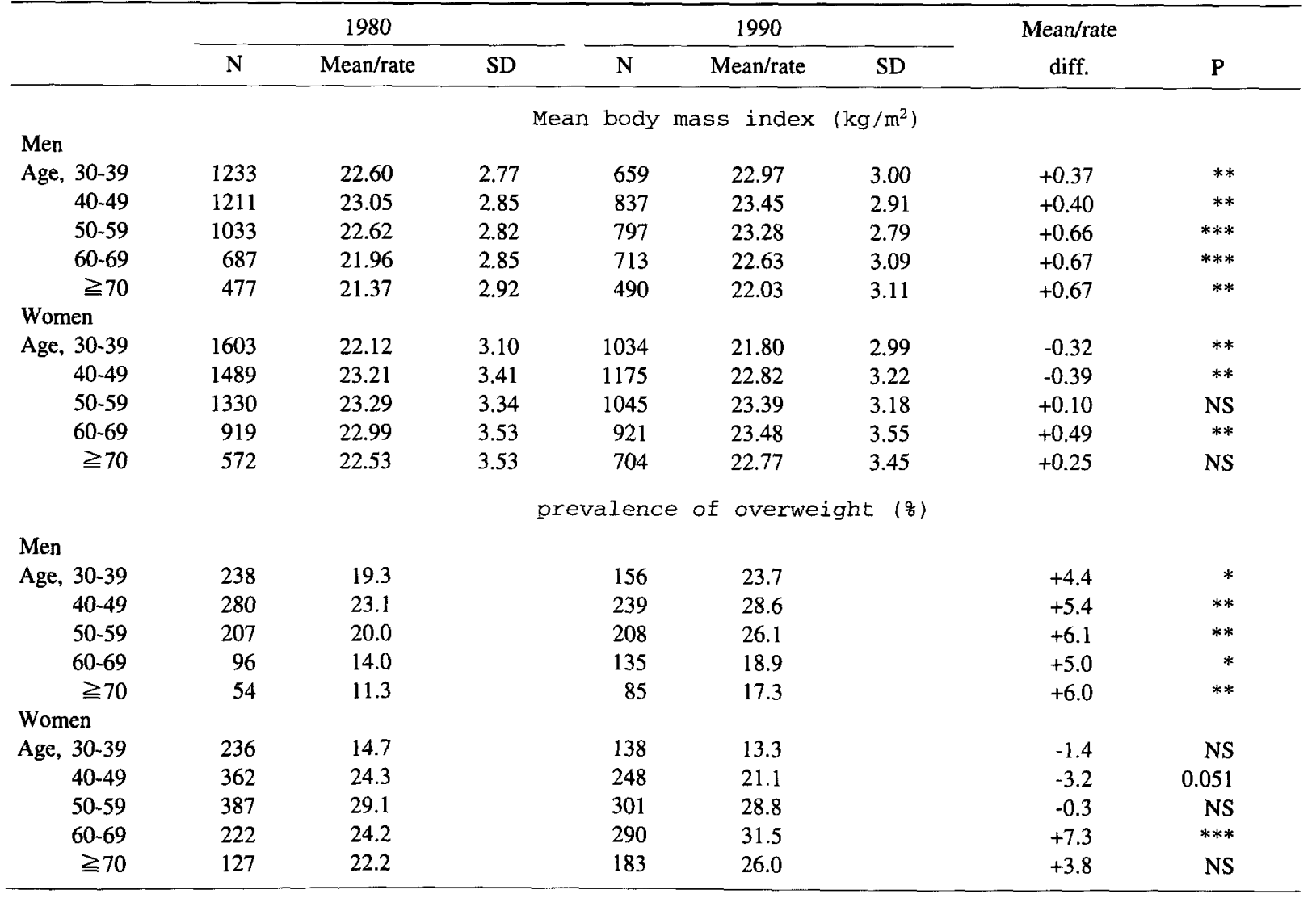

NS=not significant $(\mathrm{P}>0.05),{ }^{*} \mathrm{P}<0.05, * * \mathrm{P}<0.01, * * * \mathrm{P}<0.001$. 
years, but these differences between the 1980 and 1990 surveys were not significant. The prevalence of overweight decreased in women under 60 years, but increased in those aged $\geq 60$ years from 1980 to 1990 . Taking into consideration of birth-cohort effects on BMI, for example, the comparisons of BMI between subjects aged 30-39 years in 1980 and those aged 40-49 years in 1990 (a 10-years aging effect), Table 2 also shows that, even in women, aging is found to be associated with increasing BMI among the population under 70 years old.

Table 3 shows that after adjusting for age, smoking, alcohol consumption and daily life physical activity, mean BMI $(95 \%$ CI) significantly increased $0.49 \mathrm{~kg} / \mathrm{m}^{2}\left(0.34-0.65 \mathrm{~kg} / \mathrm{m}^{2}\right)$ in men aged 30-59, and $0.61 \mathrm{~kg} / \mathrm{m}^{2}\left(0.37-0.86 \mathrm{~kg} / \mathrm{m}^{2}\right)$ in those aged $\geq 60$ from 1980 to 1990 . In women, however, mean BMI significantly decreased $0.24 \mathrm{~kg} / \mathrm{m}^{2}\left(-0.39-0.09 \mathrm{~kg} / \mathrm{m}^{2}\right)$ in subjects aged $30-59$ and increased $0.38 \mathrm{~kg} / \mathrm{m}^{2}\left(0.12-0.64 \mathrm{~kg} / \mathrm{m}^{2}\right)$ in those aged $\geq 60$ from 1980 to 1990 .

Table 4 shows that among men and women, age-adjusted prevalence of hypertension decreased, while the prevalence of diabetes and hypercholesterolaemia increased among both younger (30-59 years) and older ( $\geq 60$ years) subjects from 1980 to 1990.

Table 3. Adjusted mean body mass index and its changes from 1980 to 1990 for men and women.

\begin{tabular}{|c|c|c|c|c|c|c|c|}
\hline & \multicolumn{2}{|c|}{1980} & \multicolumn{2}{|c|}{1990} & \multirow{2}{*}{$\begin{array}{c}\text { Mean } \\
\text { diff. }\end{array}$} & \multicolumn{2}{|c|}{ Mean diff. $95 \% \mathrm{Cl}$} \\
\hline & Mean & SE & Mean & SE & & lower & upper \\
\hline \multicolumn{8}{|c|}{ Aged $30-59$ years } \\
\hline \multirow{2}{*}{\multicolumn{8}{|c|}{$\begin{array}{l}\text { Men } \\
\text { Adjusted factor. }\end{array}$}} \\
\hline & & & & & & & \\
\hline Age only & 22.77 & 0.05 & 23.25 & 0.06 & +0.48 & +0.33 & $+0.63 * * *$ \\
\hline \multicolumn{8}{|l|}{ Age and: } \\
\hline Smoking & 22.78 & 0.05 & 23.23 & 0.06 & +0.45 & +0.30 & $+0.60 * * *$ \\
\hline Alcohol consumption & 22.75 & 0.05 & 23.27 & 0.06 & +0.51 & +0.36 & $+0.67 * * *$ \\
\hline Daily life physical activity & 22.77 & 0.05 & 23.24 & 0.06 & +0.48 & +0.33 & $+0.63 * * *$ \\
\hline All of the above factors & 22.76 & 0.05 & 23.25 & 0.06 & +0.49 & +0.34 & $+0.65 * * *$ \\
\hline \multicolumn{8}{|l|}{ Women } \\
\hline \multicolumn{8}{|l|}{ Adjusted factor. } \\
\hline Age only & 22.86 & 0.05 & 22.65 & 0.06 & -0.21 & -0.36 & $-0.07 * *$ \\
\hline \multicolumn{8}{|l|}{ Age and: } \\
\hline Smoking & 22.86 & 0.05 & 22.65 & 0.06 & -0.21 & -0.36 & $-0.07 * *$ \\
\hline Alcohol consumption & 22.87 & 0.05 & 22.63 & 0.06 & -0.24 & -0.39 & $-0.09 * *$ \\
\hline Daily life physical activity & 22.86 & 0.05 & 22.64 & 0.06 & -0.21 & -0.36 & $-0.07 * *$ \\
\hline All of the above factors & 22.87 & 0.05 & 22.63 & 0.06 & -0.24 & -0.39 & $-0.09 * *$ \\
\hline \multicolumn{8}{|c|}{ Aged $\geqq 60$ years } \\
\hline \multicolumn{8}{|l|}{ Men } \\
\hline \multicolumn{8}{|l|}{ Adjusted factor. } \\
\hline Age only & 21.71 & 0.09 & 22.39 & 0.09 & +0.68 & +0.44 & $+0.92 * * *$ \\
\hline \multicolumn{8}{|l|}{ Age and: } \\
\hline Smoking & 21.74 & 0.09 & 22.38 & 0.09 & +0.64 & +0.41 & $+0.88 * * *$ \\
\hline Alcohol consumption & 21.69 & 0.09 & 22.41 & 0.09 & +0.71 & +0.47 & $+0.96 * * *$ \\
\hline Daily life physical activity & 21.76 & 0.09 & 22.36 & 0.09 & +0.61 & +0.36 & $+0.85 * * *$ \\
\hline \multirow{2}{*}{\multicolumn{4}{|c|}{ Women }} & 0.09 & +0.61 & & $+0.86^{* * *}$ \\
\hline & & & \multicolumn{5}{|c|}{ Adjusted factor. } \\
\hline Age only & 22.80 & 0.09 & 23.19 & 0.09 & +0.40 & +0.15 & $+0.64 * *$ \\
\hline \multicolumn{8}{|l|}{ Age and: } \\
\hline Smoking & 22.81 & 0.09 & 23.18 & 0.09 & +0.37 & +0.12 & $+0.62 * *$ \\
\hline Alcohol consumption & 22.81 & 0.09 & 23.18 & 0.09 & +0.37 & +0.12 & $+0.62 * *$ \\
\hline Daily life physical activity & 22.78 & 0.09 & 23.20 & 0.09 & +0.42 & +0.16 & $+0.67 * *$ \\
\hline All of the above factors & 22.81 & 0.09 & 23.19 & 0.09 & +0.38 & +0.12 & $+0.64 * *$ \\
\hline
\end{tabular}

$* * \mathrm{P}<0.01, * * * \mathrm{P}<0.001$ 
Table 4. Age-adjusted prevalence of hypertension, diabetes and hypercholesterolaemia and their changes from 1980 to 1990 for men and women ${ }^{\text {a, b). }}$

\begin{tabular}{|c|c|c|c|}
\hline & 1980 & 1990 & $\begin{array}{l}\text { Diff. between } \\
1990 \text { to } 1980\end{array}$ \\
\hline \multicolumn{4}{|c|}{ Aged $30-59$ years } \\
\hline \multicolumn{4}{|l|}{ Men } \\
\hline Hypertension & 24.1 & 21.0 & -3.1 \\
\hline Diabetes mellitus & 5.4 & 6.5 & +1.1 \\
\hline Hypercholesterolaemia & 16.0 & 27.6 & +11.6 \\
\hline \multicolumn{4}{|l|}{ Women } \\
\hline Hypertension & 16.4 & 14.7 & -1.7 \\
\hline Diabetes mellitus & 2.1 & 3.1 & +1.0 \\
\hline Hypercholesterolaemia & 15.8 & 26.8 & +11.0 \\
\hline \multicolumn{4}{|c|}{ Aged $\geqq 60$ years } \\
\hline \multicolumn{4}{|l|}{ Men } \\
\hline Hypertension & 61.4 & 53.5 & -7.9 \\
\hline Diabetes mellitus & 10.9 & 15.2 & +4.3 \\
\hline Hypercholesterolaemia & 12.1 & 24.5 & +12.4 \\
\hline \multicolumn{4}{|l|}{ Women } \\
\hline Hypertension & 59.9 & 58.4 & -1.5 \\
\hline Diabetes mellitus & 6.0 & 8.4 & +2.4 \\
\hline Hypercholesterolaemia & 27.9 & 47.7 & +19.8 \\
\hline
\end{tabular}

a) Definition for hypertension, diabetes mellitus and hypercholesterolaemia, see Table 1 notes.

b) Age-adjustment by using the 1985 Standard Population of Japan.

\section{Body mass index and risk of hypertension, diabetes and hyper- cholesterolaemia}

The associations between BMI (by quartiles) and risk of hypertension, diabetes and hypercholesterolaemia are presented in Table 5 according to two age groups (30-59 and $\geq 60$ years). In general, increased BMI was consistently and significantly associated with an increasing risk of hypertension, diabetes and hypercholesterolaemia in both genders in the 1980 and 1990 surveys, with the exception of the multi-adjusted odds ratios for the risk of diabetes in men and women aged 3059 in 1990 , which appeared to be inversely associated with BMI. However, these latter odds ratios were not significant.

\section{Body mass index and lifestyle factors}

Table 6 shows that among men, cu-smokers had lower BMI compared with never smokers and ex-smokers. Among cusmokers, however, an increase in the number of cigarettes smoked daily was associated with increased mean BMI, and these associations were significant in those aged 30-59 years in the 1980 and 1990 surveys. Ex-smokers appeared to have slightly lower BMI than never smokers in the 1980 survey, and a slightly higher BMI in the 1990 survey. Drinkers (ex- and cudrinking) appeared to have higher mean BMI than never drinkers in 1980 and 1990 surveys, but these differences were not significant. Subjects with light physical activity had the highest age-adjusted mean BMI in the 1980 and 1990 surveys, except that those aged 30-59 years old in the 1980 survey had a slightly lower mean BMI than those with heavy physical activity.

In women aged $\geq 60$ years in the 1980 survey, cu-smokers had significantly lower age-adjusted mean BMI than ex-smokers and never smokers. Among cu-smokers, an increase in the number of cigarettes smoked daily was significantly associated with increasing mean BMI in those aged 30-59 years, while the association was not clear in those aged $\geq 60$ in the 1980 and 1990 surveys. There was no clear association between drinking and BMI in women, although cu-drinkers had a lower BMI than never drinkers. Women whose physical activity was categorized as "light" appeared to have lower age-adjusted mean BMI than those with moderate and heavy physical activities in both the 1980 and 1990 surveys, with the exception of those aged $\geq 60$ in the 1990 survey.

Table 7 shows the results of the associations between BMI and lifestyle factors by combining the 1980 and 1990 surveys. Prior to this analysis, these associations were initially analyzed for the 1980 and 1990 surveys separately (by adjusting for age and lifestyle factors), and then for the combined sample of the two surveys (by adjusting for survey year, age and lifestyle factors). The separate results for the 1980 and 1990 surveys were not shown because they were similar to the results of the combined sample. Model 1 indicated that among all of the subjects, BMI was negatively and significantly associated with cu- 
Table 5. Multi-adjusted odds ratios $(95 \% \mathrm{Cl}$ ) for body mass index (by quartiles) associated with the prevalence of hypertension, diabetes mellitus and hypercholesterolaemia by two age groups in 1980 to 1990 for men and women a,b,c).

\begin{tabular}{|c|c|c|c|c|c|c|c|c|c|}
\hline \multicolumn{3}{|c|}{ Hypertension } & \multicolumn{4}{|c|}{ Diabetes mellitus } & \multicolumn{3}{|c|}{ Hypercholesterolaemia } \\
\hline Aged $30-59$ years & & ged $\geqq 60$ years & & ged $30-59$ years & & yed $\geqq 60$ years & Age & d $30-59$ years & Aged $\geqq 60$ years \\
\hline $95 \% \mathrm{Cl}$ & & $95 \% \mathrm{Cl}$ & & $95 \% \mathrm{Cl}$ & & $95 \% \mathrm{Cl}$ & & $95 \% \mathrm{Cl}$ & $95 \% \mathrm{Cl}$ \\
\hline upper & OR & lower & OR & lower & OR & lower & OR & upper & lower \\
\hline
\end{tabular}

Men

\begin{tabular}{|c|c|c|c|c|c|c|c|c|c|c|c|c|c|c|c|c|c|c|}
\hline BMI-Q1 & 1 & & & 1 & & & 1 & & & 1 & & & 1 & & & 1 & & \\
\hline BMI-Q2 & 1.52 & 1.14 & 2.03 & 2.07 & 1.46 & 2.93 & 1.12 & 0.72 & 1.74 & 1.23 & 0.75 & 2.01 & 1.60 & 1.14 & 2.25 & 1.44 & 0.88 & 2.35 \\
\hline BMI-Q3 & 2.24 & 1.69 & 2.97 & 2.35 & 1.60 & 3.44 & 1.11 & 0.71 & 1.75 & 1.05 & 0.62 & 1.78 & 3.17 & 2.30 & 4.36 & 1.60 & 0.97 & 2.62 \\
\hline BMI-Q4 & 4.05 & 3.06 & 5.35 & 2.41 & 1.56 & 3.73 & 1.63 & 1.06 & 2.51 & 1.90 & 1.10 & 3.28 & 4.64 & 3.38 & 6.36 & 2.21 & 1.30 & 3.76 \\
\hline Vomen & & & & & & & & & & & & & & & & & & \\
\hline BMI-Q1 & 1 & & & 1 & & & 1 & & & 1 & & & 1 & & & 1 & & \\
\hline BMI-Q2 & 1.08 & 0.78 & 1.49 & 1.93 & 1.36 & 2.74 & 1.11 & 0.57 & 2.14 & 1.28 & 0.63 & 2.58 & 1.29 & 0.99 & 1.67 & 1.61 & 1.13 & 2.31 \\
\hline BMI-Q3 & 2.16 & 1.61 & 2.90 & 2.89 & 2.04 & 4.08 & 0.98 & 0.49 & 1.93 & 1.57 & 0.81 & 3.02 & 1.43 & 1.10 & 1.85 & 2.03 & 1.44 & 2.86 \\
\hline BMI-Q4 & 3.88 & 2.93 & 5.13 & 4.04 & 2.86 & 5.71 & 2.23 & 1.25 & 3.97 & 1.92 & 1.02 & 3.59 & 2.21 & 1.73 & 2.82 & 2.14 & 1.53 & 2.98 \\
\hline
\end{tabular}

1990 survey

Men

\begin{tabular}{|c|c|c|c|c|c|c|c|c|c|c|c|c|c|c|c|c|c|c|}
\hline BMI-Q1 & 1 & & & 1 & & & 1 & & & 1 & & & 1 & & & 1 & & \\
\hline BMI-Q2 & 1.57 & 1.05 & 2.36 & 1.31 & 0.92 & 1.88 & 0.70 & 0.42 & 1.16 & 1.90 & 1.14 & 3.14 & 2.20 & 1.50 & 3.23 & 1.37 & 0.90 & 2.11 \\
\hline BMI-Q3 & 1.96 & 1.33 & 2.91 & 1.90 & 1.33 & 2.70 & 0.69 & 0.43 & 1.12 & 1.88 & 1.15 & 3.07 & 3.27 & 2.27 & 4.71 & 2.30 & 1.55 & 3.42 \\
\hline BMI-Q4 & 3.69 & 2.53 & 5.38 & 2.48 & 1.72 & 3.57 & 0.72 & 0.45 & 1.16 & 2.84 & 1.76 & 4.57 & 5.63 & 3.93 & 8.06 & 2.70 & 1.81 & 4.02 \\
\hline \multicolumn{19}{|l|}{ Women } \\
\hline BMI-Q1 & 1 & & & 1 & & & 1 & & & 1 & & & 1 & & & 1 & & \\
\hline BMI-Q2 & 2.00 & 1.33 & 3.01 & 1.76 & 1.25 & 2.47 & 0.64 & 0.35 & 1.17 & 1.52 & 0.87 & 2.63 & 1.16 & 0.90 & 1.49 & 1.44 & 1.06 & 1.97 \\
\hline BMI-Q3 & 3.03 & 2.05 & 4.49 & 2.46 & 1.75 & 3.46 & 0.78 & 0.44 & 1.39 & 1.48 & 0.86 & 2.56 & 1.75 & 1.37 & 2.24 & 1.49 & 1.09 & 2.02 \\
\hline BMI-Q4 & 6.67 & 4.59 & 9.70 & 3.36 & 2.43 & 4.64 & 1.07 & 0.63 & 1.81 & 1.24 & 0.73 & 2.10 & 2.19 & 1.72 & 2.79 & 1.57 & 1.18 & 2.09 \\
\hline
\end{tabular}

a) Subjects were classified as having hypertension for those who had SBP $\geqq 160$ or DBP $\geqq 95 \mathrm{mmHg}$, or who were under treatment with antihypertensive agents. Subjects were classified as diabetes mellitus (DM) for any of the following conditions: self-reported history of DM or positive urinary glucose test. Hypercholesterolaemia was defined as total cholesterol $\geqq 220 \mathrm{mg} / \mathrm{dl}$.

b) BMI-Q1, BMI-2, BMI-3 and BMI-4 are for quariles of body mass index 1 (less than $\left.20.52 \mathrm{~kg} / \mathrm{m}^{2}\right), 2\left(20.52-22.51 \mathrm{~kg} / \mathrm{m}^{2}\right), 3(22.52-$ $\left.24.68 \mathrm{~kg} / \mathrm{m}^{2}\right)$ and $4\left(24.69 \mathrm{~kg} / \mathrm{m}^{2}\right.$ or more). Odds ratios were calculated in comparison to quartile 1 .

c) Multi-adjusted factors: age (year), smoking $(0=$ never smoking, $1=$ ex-smoking and $2=\mathrm{cu}$-smoking), drinking $(0=$ never drinking, $1=$ ex-drinking, $2=c u$-drinking) and daily life physical activity ( $0=$ light, $1=$ moderate and $2=$ heavy).

smoking in men aged 30-59 and $\geq 60$ years, and in women aged $\geq 60$ years. There were no significant associations between BMI and ex-smoking in either gender. BMI was positively and significantly associated with alcohol consumption in men. This association, however, was negative and non-significant in women. In men, BMI was negatively and significantly associated with daily life physical activity in those aged $\geq 60$ years, while this association was significant and positive in women aged $30-59$ years.

Among cu-smokers, the associations between BMI and lifestyle factors were examined by model 2 . A significant positive association between BMI and the number of cigarettes smoked daily was observed in both genders aged 30-59 years. Among male cu-smokers, alcohol consumption was positively, and physical activity was negatively, associated with BMI, but these associations were not significant. In female cu-smokers, BMI was negatively and significantly associated with alcohol consumption in those aged 30-59 years, while there was no significant association between BMI and physical activity.

\section{DISCUSSION}

Our study has three important features: (1) the results are based on the most recent representative nationwide surveys in Japan, (2) it is the first detailed study to focus on the changes in BMI and the relationships between BMI and other cardiovascular factors in Japanese, and (3) the results may be informative for other Asian countries, since with their economic development and possible lifestyle westernization, they may experience the same changes in cardiovascular factors as Japan. 
Table 6. Age-adjusted mean body mass index $\left(\mathrm{kg} / \mathrm{m}^{2}\right)$ and lifestyle factors by two age groups in 1980 and 1990 for men and women.

\begin{tabular}{|c|c|c|c|c|c|c|c|c|}
\hline & \multicolumn{4}{|c|}{1980} & \multicolumn{4}{|c|}{1990} \\
\hline & \multirow{2}{*}{$\frac{\text { Aged } 30-59}{\text { Mean }}$} & \multirow[b]{2}{*}{ SE } & \multirow{2}{*}{$\frac{\text { Aged } \geqq 60}{\text { Mean }}$} & \multirow[b]{2}{*}{$\mathrm{SE}$} & \multirow{2}{*}{$\frac{\text { Aged 30-59 }}{\text { Mean }}$} & \multirow[b]{2}{*}{$\mathrm{SE}$} & \multirow{2}{*}{$\frac{\text { Aged } \geqq 60}{\text { Mean }}$} & \multirow[b]{2}{*}{ SE } \\
\hline & & & & & & & & \\
\hline \multicolumn{9}{|l|}{ Men } \\
\hline \multicolumn{9}{|l|}{ Smoking status } \\
\hline Never smoker & 23.32 & 0.11 & 22.51 & 0.19 & 23.47 & 0.13 & 22.32 & 0.20 \\
\hline Ex-smoker & 22.94 & 0.12 & 22.12 & 0.16 & 23.50 & 0.14 & 22.95 & 0.15 \\
\hline $\mathrm{Cu}$-smoker & 22.56 & 0.06 & 21.27 & 0.11 & 23.09 & 0.08 & 22.03 & 0.13 \\
\hline ANCOVA test & $* * *$ & & $* * *$ & & $* * *$ & & $* *$ & \\
\hline \multicolumn{9}{|l|}{ Cu-smokers } \\
\hline $1-20 \mathrm{cig} / \mathrm{day}$ & 22.30 & 0.08 & 21.30 & 0.12 & 22.75 & 0.10 & 22.04 & 0.14 \\
\hline $21-40 \mathrm{cig} / \mathrm{day}$ & 22.86 & 0.10 & 21.44 & 0.26 & 23.51 & 0.13 & 22.47 & 0.33 \\
\hline$\geqq 41 \mathrm{cig} /$ day & 23.06 & 0.22 & 21.93 & 0.76 & 24.15 & 0.38 & 22.24 & 1.54 \\
\hline ANCOVA test & $* * *$ & & NS & & $* *$ & & NS & \\
\hline \multicolumn{9}{|l|}{ Alcohol consumption } \\
\hline Never drinking & 22.57 & 0.11 & 21.57 & 0.16 & 23.16 & 0.10 & 22.18 & 0.14 \\
\hline Ex-drinking & 23.10 & 0.25 & 21.82 & 0.25 & 23.36 & 0.30 & 22.38 & 0.25 \\
\hline $\mathrm{Cu}$-drinking & 22.79 & 0.05 & 21.76 & 0.11 & 23.30 & 0.08 & 22.55 & 0.13 \\
\hline ANCOVA test & NS & & NS & & NS & & NS & \\
\hline \multicolumn{9}{|c|}{ Daily life physical activity } \\
\hline Light & 22.77 & 0.09 & 21.97 & 0.14 & 23.37 & 0.09 & 22.47 & 0.12 \\
\hline Moderate & 22.71 & 0.06 & 21.60 & 0.12 & 23.20 & 0.09 & 22.32 & 0.16 \\
\hline Heavy & 22.99 & 0.13 & 21.56 & 0.23 & 23.06 & 0.16 & 22.03 & 0.30 \\
\hline ANCOVA test & NS & & NS & & NS & & NS & \\
\hline \multicolumn{9}{|l|}{ Women } \\
\hline \multicolumn{9}{|l|}{ Smoking status } \\
\hline Never smoker & 22.86 & 0.05 & 22.91 & 0.10 & 22.65 & 0.06 & 23.25 & 0.09 \\
\hline Ex-smoker & 22.83 & 0.35 & 23.39 & 0.49 & 23.31 & 0.37 & 22.70 & \\
\hline $\mathrm{Cu}$-smoker & 22.61 & 0.16 & 21.94 & 0.27 & 22.81 & 0.17 & 22.58 & 0.44 \\
\hline ANCOVA test & NS & & $* *$ & & NS & & NS & 0.31 \\
\hline \multicolumn{9}{|l|}{ Cu-smokers } \\
\hline $1-20 \mathrm{cig} /$ day & 22.47 & 0.17 & 21.93 & 0.32 & 22.57 & 0.20 & 22.44 & 0.30 \\
\hline $21-40 \mathrm{cig} / \mathrm{day}$ & 22.99 & 0.52 & 22.96 & 1.18 & 23.78 & 0.67 & 24.49 & 0.98 \\
\hline$\geqq 41 \mathrm{cig} /$ day & 26.79 & 1.64 & 17.84 & 3.92 & 31.38 & 2.50 & - & - \\
\hline ANCOVA test & $*$ & & NS & & $* *$ & & NS & \\
\hline \multicolumn{9}{|l|}{ Alcohol consumption } \\
\hline Never drinking & 22.88 & 0.06 & 22.83 & 0.10 & 22.69 & 0.06 & 23.20 & 0.09 \\
\hline Ex-drinking & 22.75 & 0.40 & 23.61 & 0.62 & 23.13 & 0.51 & 21.32 & 0.85 \\
\hline $\mathrm{Cu}$-drinking & 22.69 & 0.11 & 22.63 & 0.24 & 22.47 & 0.19 & 23.18 & 0.48 \\
\hline ANCOVA test & NS & & NS & & NS & & NS & \\
\hline \multicolumn{9}{|c|}{ Daily life physical activity } \\
\hline Light & 22.71 & 0.07 & 22.67 & 0.13 & 22.60 & 0.08 & 23.29 & 0.10 \\
\hline Moderate & 22.91 & 0.07 & 22.88 & 0.14 & 22.70 & 0.08 & 22.81 & 0.18 \\
\hline Heavy & 23.30 & 0.24 & 23.28 & 0.32 & 23.02 & 0.19 & 23.28 & 0.45 \\
\hline ANCOVA test & NS & & NS & & NS & & NS & \\
\hline
\end{tabular}

NS=not significant $(\mathrm{P}>0.05),{ }^{*} \mathrm{P}<0.05, * * \mathrm{P}<0.01, * * * \mathrm{P}<0.001$.

ANCOVA test=analysis of covariance. 
Table 7. Multiple linear regression models ${ }^{\text {a) }}$ for the associations between body mass index and lifestyle factors among all of the subjects (Model 1), and among cu-smoker only (Model 2) for men and women.

\begin{tabular}{|c|c|c|c|c|c|}
\hline & \multicolumn{2}{|c|}{ Subjects aged $30-59$} & \multicolumn{3}{|c|}{ Subjects aged $\geqq 60$} \\
\hline & B & SE & B & $\mathrm{SE}$ & \\
\hline \multicolumn{6}{|c|}{ Model 1 among all subjects } \\
\hline \multicolumn{6}{|c|}{ Men } \\
\hline Sample size (n) & \multicolumn{2}{|c|}{5759} & \multicolumn{3}{|c|}{2354} \\
\hline Cu-smoking & -0.625 & $0.098 * * *$ & -0.818 & 0.165 & *** \\
\hline Ex-smoking & -0.224 & $0.124 \mathrm{NS}$ & 0.080 & 0.179 & NS \\
\hline Drinking & 0.120 & $0.045^{* *}$ & 0.180 & 0.068 & $* *$ \\
\hline Physical activity & -0.025 & $0.058 \mathrm{NS}$ & -0.202 & 0.092 & $*$ \\
\hline \multicolumn{6}{|l|}{ Women } \\
\hline Sample size (n) & \multicolumn{2}{|c|}{7674} & \multicolumn{3}{|c|}{3079} \\
\hline Cu-smoking & -0.001 & $0.128 \mathrm{NS}$ & -0.769 & 0.218 & $* * *$ \\
\hline Ex-smoking & 0.263 & $0.260^{\mathrm{NS}}$ & -0.045 & 0.337 & NS \\
\hline Drinking & -0.091 & $0.052 \mathrm{NS}$ & -0.081 & 0.115 & NS \\
\hline Physical activity & 0.194 & $0.062 * *$ & 0.050 & 0.109 & NS \\
\hline \multicolumn{6}{|c|}{ Model 2 among cu-smokers } \\
\hline \multicolumn{6}{|c|}{ Men } \\
\hline Sample size (n) & \multicolumn{2}{|c|}{3635} & \multicolumn{3}{|c|}{1207} \\
\hline No. of smoked daily & 0.547 & $0.077 * * *$ & 0.284 & 0.196 & NS \\
\hline Drinking & 0.066 & $0.059 \mathrm{NS}$ & 0.153 & 0.095 & NS \\
\hline Physical activity & -0.046 & $0.073 \mathrm{NS}$ & -0.104 & 0.127 & NS \\
\hline \multicolumn{6}{|l|}{ Women } \\
\hline Sample size (n) & \multicolumn{2}{|c|}{745} & \multicolumn{3}{|c|}{292} \\
\hline No. of smoked daily & 1.504 & $0.377 * * *$ & 0.914 & 0.742 & NS \\
\hline Drinking & -0.351 & $0.135 * *$ & -0.301 & 0.282 & NS \\
\hline Physical activity & 0.053 & $0.210^{\mathrm{NS}}$ & -0.001 & 0.392 & NS \\
\hline
\end{tabular}

a) Adjustment for survey year, age and other factors in these models.

NS $=$ not significant $(\mathrm{P}>0.05),{ }^{*} \mathrm{P}<0.05,{ }^{*} * \mathrm{P}<0.01,{ }^{* * *} \mathrm{P}<0.001$.

\section{Changes in body mass index}

Our findings indicate that BMI significantly increased in Japanese men aged $\geq 30$ and in women aged $\geq 60$ years. In contrast, BMI significantly decreased in women aged 30-59. These associations were independent of age, smoking, alcohol consumption and daily physical activity. Similar to the results in BMI, the prevalence of overweight increased in men in each 10-year age-group. In women, however, the prevalence of overweight decreased in those under 60 years, and increased in those over 60 years old.

Among men, increases in BMI and the prevalence of overweight have been reported in several Western countries ${ }^{10-13}$. Among middle-aged women, increases in BMI and the prevalence of overweight have also been recently seen in the United Kingdom, the United States, Sweden and Australia, but not in Italy, Finland or The Netherlands ${ }^{12-18)}$. There are comparatively few studies in Asian countries. In China, Ge et al., using China Nutrition Surveys, reported that mean BMI increased from 1980 to 1989 in Chinese men and women, and the proportion of obesity (BMI $>25 \mathrm{~kg} / \mathrm{m}^{2}$ ) increased $4.8 \%$ for urban resi- dents and $2 \%$ for rural residents aged $20-45$ years ${ }^{19)}$. In Japan, the trend in BMI from 1956 to 1980 was reported by Ueshima et al. ${ }^{20)}$ In a recent report by Sakata et al., the changes of BMI from 1970 to 1990 were described, while other potential confounding factors were not considered in their data analyses, such as smoking, alcohol consumption and daily life physical activity ${ }^{21)}$. Thus, our study has extended previous studies and provides more detailed information on the changes in BMI.

The increase in BMI and the prevalence of overweight in Japanese men aged $\geq 30$ and women aged $\geq 60$ years may be due to changes in several factors such as dietary, social and demographic, and behavioural factors. Our study suggests that smoking, alcohol consumption and daily life physical activity had only a small effect on mean level of BMI (Table 3). Changes in diet may have the strongest effect. The Japan National Nutrition Surveys in 1980 and 1989 indicated that the percentage of calories supply from fat increased from $22.6 \%$ to $25.7 \%$, while that from cereals decreased from $48 \%$ to $45.1 \%$. Fish and bean consumption has changed little, while meat, milk and milk product consumption has gradually increased in 
Japanese from 1980 to $1989^{3)}$. The reason for the decrease in BMI among young women is not clear. It is possible that young Japanese women may have prevented overweight by paying attention to their diet over the past 10 years. However, among both genders who were aged less than 70 years, the associations between aging and increased BMI (birth-cohort effect) suggest that both effects of aging and changes in lifestyles on BMI should be considered in public health programme for control of body weight.

The present study also shows a decrease in prevalence of hypertension, and increases in prevalence of diabetes and hypercholesterolaemia from 1980 to 1990 (Table 4). Several studies have confirmed that the decrease in prevalence of hypertension is mainly because of improvements in the control of high blood pressure in both lifestyle changes (such as decrease in salt intake), and medical treatment ${ }^{1,20,21}$. However, the increases in prevalence of diabetes and hypercholesterolaemia are strongly suggested to be associated with changes in dietary habits (such as increase in fat intake), and increase in body weight over the past 10 years $3,5,2$ ).

\section{Body mass index and risk of hypertension, DM and hypercho- lesterolaemia}

Hypertension, DM and hypercholesterolaemia are wellestablished risk factors for coronary heart disease. A local study in Kyushu, Japan, reported that increased BMI was significantly associated with a high risk of diabetes ${ }^{22}$. In our study, we confirmed that increased BMI was significantly associated with the risk of hypertension, DM and hypercholesterolaemia in both men and women. The association between BMI and DM showed some complicated or inverse associations in those aged 30-59 the 1990 survey (Table 5), while these results may be due to chance $(P>0.05)$. In our present study, a possible limitation was that the definition of DM was based on the subject's self-reported medical history and the results of a urinary glucose test. There were no further examinations to confirm disease status. Therefore, misclassification or underestimation of the prevalence of DM might have occurred ${ }^{5}$.

\section{Body mass index and lifestyle factors}

Smokers tend to weigh less and have a lower BMI than never smokers, and people who stop smoking tend to gain weight and have an increased BMI ${ }^{23-26)}$. Some studies have also indicated that among smokers, BMI is positively associated with an increase in the number of cigarettes smoked 23.26). The results in our study are consistent with these previous results. The mechanism of the association between BMI and smoking is not completely understood ${ }^{27}$. One explanation is that smoking reduces the appetite. Among smokers, however, heavy smoking may be part of a cluster of substance-abuse behaviours, including over-eating and alcohol consumption ${ }^{23,28)}$.

Previous reports on the associations between BMI and alcohol consumption are inconsistent ${ }^{2326)}$. For example, Rasky et al. reported that alcohol consumption was significantly associated with a high relative weight in men, whereas no such relation was found in women ${ }^{23}$. Tavani et al ${ }^{26)}$. found no significant differences in age-adjusted mean BMI between drinkers and nondrinkers. Our study shows a positive relationship between BMI and alcohol consumption in men. One reason may be that most Japanese male drinkers are moderate or heavy drinkers, and they often eat more fatty food than never drinkers and light drinkers. Among women, however, a significant negative association between BMI and drinking was observed in cu-smokers aged 30-59 years. One of the explanations is that most Japanese female drinkers have light drinking habits. It should be noted that, in the present study, categories of drinking habits in 1980 and 1990 surveys were not well comparable (Table 1) due to the different definitions in their questionnaires. In the 1990 survey, prevalence of cu-drinkers may have been under-estimated for both men and women, and some of cu-drinkers (especially, light drinkers) may have been classified as never drinkers ${ }^{33}$. This limitation may lead to under- or over-estimate the associations between alcohol consumption and BMI, and other factors. To keep this in mind, the present results may provide some evidence for further studies.

An inverse association between daily life physical activity and BMI in men and women has been supported by some studies ${ }^{2329-32)}$. In our study, after adjusting for survey year, age, smoking and alcohol consumption, this inverse association was seen in men. In women, however, BMI was positively associated with daily life physical activity, and this association was significant in those aged 30-59 years. It should be noted that in the present study, physical activity was generally classified according to the subject's occupational and leisure time physical activity, because detailed information on physical activity was not available from the 1980 and 1990 surveys. Therefore, from the study, we can not make a conclusion regarding this association between BMI and physical activity in Japanese.

In conclusion, despite of some limitations, using the most recent large Japanese surveys, our results show that both BMI and the prevalence of overweight increased in men aged $\geq 30$ and in women aged $\geq 60$ years. In young adult women, however, mean BMI and the prevalence of overweight have decreased. Further studies are required to examine the possible determinants. Our findings also suggest that even in the Japanese population who are characterized by relative low BMI, and with a low incidence and mortality from coronary heart disease, BMI is significantly associated with several established risk factors of coronary heart disease, such as hypertension, diabetes, hypercholesterolaemia and heavy smoking. 


\section{ACKNOWLEDGMENTS}

The study was supported by a Research Grant for Cardiovascular Disease (7C-2) from the Ministry of Health and Welfare of Japan. Dr. Longjian Liu, from Department of Epidemiology, Chongqing University of Medical Science, China, was awarded a fellowship (L97559) from the Japan Society for the Promotion of Science for his study in the Department of Health Science, Shiga University of Medical Science, Otsu, Japan.

\section{REFERENCES}

1. Ueshima $H$, Tatara $K$, Asakura S. Declining mortality from ischemic heart disease and changes in coronary risk factors in Japan, 1956-1980. Am J Epidemiol 1987;125:62-72.

2. Tanaka H, Date C, Chen $\mathrm{H}$ et al. Ressearch Activities of Epidemiology in Japan, Cardiovascular Disease, A brief review of epidemiological studies on ischemic heart disease in Japan. J Epidemiol 1996; 6:S59-S59.

3. Okayama A, Ueshima $H$, Marmot M G et al. Changes in total serum cholesterol and other risk factors for cardiovascular disease in Japan, 1980-1989. Int J Epidemol 1993;22:1038-1047.

4. Okayama A, Ueshima $H$, Marmot $M$ G, Elliott $P$, Yamakawa M, Kita Y. Different trends in serum cholesterol levels among rural and urban populations aged 4059 in Japan from 1960 to 1990. J Clin Epidemol 1995;48:329-337.

5. Ohmura T, Ueda K, Kiyohara Y et al. Prevalence of Type 2 (non-insuline-dependent) diabetes mellitus and impaired glucose tolerance in the Japanese general population: the Hisayama study. Diabetologia 1993;36:11981203.

6. Ministry of Health and Welfare of Japan. National survey on circulatory disorders 1980. Tokyo: Ministry of Health and Welfare, 1983 (in Japanese with English summary).

7. Ministry of Health and Welfare of Japan. National survey on circulatory disorders 1990. Tokyo: Ministry of Health and Welfare, 1993 (in Japanese with English summary).

8. Galanis DJ, Harris T, Sharp DS, Petrovitch H. Relative weight, weight change, and risk of coronary heart disease in the Honolulu Heart Program. Am J Epidemiol 1998;147:379-86.

9. SPSS software 7.5, 1996; SPSS Inc., 444 N. Michigan Avenue, Chicago, $\mathbb{L}, 60611$.

10. Seidell JC. Time trends in obesity: an epidemiological perspective. Horm. Metab. Res. 1997;29:155-158.

11. Simmons G, Jackson R, Swinburn B et al. The increaseing prevalence of obesity in New Zealand: is it related to recent trends in smoking and physical activity? N Z Med
J 1996;109:90-2.

12. Kuskowska-Wolk A, Bergstrom R. Trends in body mass index and prevalence of obesity in Swedish men 1980-89. J Epidemiol Community Health 1993;47:103-108.

13. Kuskowska-Wolk A, Bergstrom R. Trends in body mass index and prevalence of obesity in Swedish women 198089. J Epidemiol Community Health 1993;47:195-199.

14. Kuczmarski RJ, Flegal KM, Campbell SM et al. Increasing prevalence of overweight among US adults. JAMA. 1994;272:205-211.

15. Pietinen $P$, Vartiainen $E$, Mannisto $S$. Trends in body mass index and obesity among adults in Finland from 1972 to 1992. Int J Obes 1996;20:114-120.

16. Bennett SA, Magnus $P$. Trends in cardiovascular risk factors in Australia: Results from the National Heart Foundation's Risk Factor Prevalence Study, 1980-1989. Med J Aust, 1994;161:519-527.

17. The Research Group ATS-RF2-OB43 of the Italian National Research Council: Time trends of some cardiovascular risk factors in Italy. Am J Epidemiol 1987;126;95-103.

18. Blokstra A, Kromhout D. Trends in obesity in young adults in The Netherlands from 1974 to 1986 . Int J Obes 1991;15:513-521.

19. Ge K, Weisell R, Guo X et al. The body mass index of Chinese adults in the 1980s. Eur J Clin Nutr 1994;48:S148-S154.

20. Ueshima H, Tatara K, Asakura S, Okamoto M. Declining trends in blood pressure level and the prevalence of hypertension and changes in related factors in Japan, 1956-1980. J Chronic Dis 1987;40:137-147.

21. Sakata K, Labarthe D R. Changes in cardiovascular disease risk factors in three Japanese National Surveys 19711990. J Epidemiol 1996; 6:93-107.

22. Todoroki I, Shinchi K, Kono S, Imanishi K. Lifestyle and glucose tolerance: A cross-sectional study of Japanese men. Ann Epidemiol 1994;4:363-368.

23. Rasky E, Stronegger W J, Freidl W. The relationship between body weight and patterns of smoking in women and men. Int J Epidemol 1996; 25: 1028-1212.

24. Boyle CA, Dobson AJ, Egger $\mathrm{G}$ et al. Can the increasing weight of Australians be explained by the decreasing prevalence of cigarette smoking ? Int J Obes 1994;18:5560.

25. Fogelholm M, Mannisto S, Vartiainen $\mathrm{E}$ et al. Determinants of energy balance and overweight in Finland 1982 and 1992. Int J Obes 1996;20:1097-1104.

26. Tavani A, Negri E, Vecchia CL. Deterninants of body mass index: a study from Northern Italy. Int $\mathrm{J}$ Obes 1994;18:497-502.

27. Neese RA, Benowitz NL, Hoh R et al. Metabolic interactions between surplus dietary energy intake and cigarette 
smoking or its cessation. Am J Physiol 1994;267:E102334.

28. Nakamura Y, Sakata K, Yanagawa H. Relationships between smoking habits and other behavior factors among males: from the results of the 1990 national cardiovascular survey in Japan. J Epidemiol. 1996;6:87-91.

29. Sundquist J, Johansson SE. The influence of socioeconomic status, ethnicity and lifestyle on body mass index in a longitudinal study. Int J Epidemiol 1998;27:57-63.

30. Folsom AR, Caspersen CJ, Taylor HL et al. Leisure time physical activity and its relationship to coronary risk factors in a population-based sample: The Minnesota Heart
Study. Am J Epidemiol 1985;121:570-9.

31. Dannenberg AL, Keller JB, Wilson PWF, Castelli WP. Leisure time physical activity in the Framingham Offspring Study: description, seasonal variation, and risk factor correlates. Am J Epidemiol 1989;129:76-88.

32. DiPietro L, Williamson DF, Caspersen CJ, Eaker E. The descriptive epidemiology of selected physical activities and body weight among adults trying to lose weight: the Behavioral Risk Factor Surveillance System survey, 1989. Int J Obes 1993;17:69-76.

33. Y Itokawa, K Kuriyama and $\mathrm{K}$ Yasumoto: Alcohol and Nutrition. P38-57, Tokyo, Japan, 1992, (in Japanese). 